\title{
Ohmic contacts based on Pd to indium phosphide Gunn diodes
}

\author{
A.E. Belyaev ${ }^{1}$, N.S. Boltovets ${ }^{2}$, A.V. Bobyl ${ }^{3}$, A.V. Zorenko ${ }^{2}$, I.N. Arsentiev ${ }^{3}$, V.P. Kladko ${ }^{1}$, \\ V.M. Kovtonyuk ${ }^{2}$, R.V. Konakova ${ }^{1}$, Ya.Ya. Kudryk ${ }^{1}$, A.V. Sachenko ${ }^{1}$, V.S. Slipokurov ${ }^{1}$, \\ A.S. Slepova ${ }^{2}$, N.V. Safryuk ${ }^{1}$, A.I. Gudymenko ${ }^{1}$, V.V. Shynkarenko ${ }^{1}$ \\ ${ }^{I} V$. Lashkaryov Institute of Semiconductor Physics, NAS of Ukraine, \\ 41, prospect Nauky,03650 Kyiv,Ukraine, e-mail: konakova@isp.kiev.ua \\ ${ }^{2}$ State Enterprise Research Institute "Orion”, 03057 Kyiv, Ukraine \\ ${ }^{3}$ A.F. Ioffe Physical-Technical Institute, Russian Academy of Sciences, \\ 197101, St. Petersburg, Russian Federation
}

\begin{abstract}
Experimental data on manufacturing the ohmic contacts $\mathrm{Au}-\mathrm{Ti}-\mathrm{Pd}-n^{+}-\mathrm{InP}$, formed using vacuum deposition of metal onto a heated to $300{ }^{\circ} \mathrm{C}$ substrate representing an epitaxial $n^{+}-n-n^{++}-n^{+++}$-InP structure. The specific contact resistance measured at room temperature was about $7 \cdot 10^{-5} \mathrm{Ohm} \cdot \mathrm{cm}^{2}$. Voltage-current characteristics within the temperature range 110 to $380 \mathrm{~K}$ are linear. Gunn diodes with such contacts, which were made as a straight mesa-structure in a pulsed mode (pulse duration of $100 \mathrm{~ns}$, pulse ratio of 1000 , operating current of $2.2 \mathrm{~A}$ ), generated the microwave power $\sim 10 \mathrm{~mW}$ in the V-band.
\end{abstract}

Keywords: ohmic contact, specific contact resistance, indium phosphide Gunn diode, heating temperature.

Manuscript received 08.04.15; revised version received 10.07.15; accepted for publication 03.09.15; published online 30.09.15.

\section{Introduction}

Indium phosphide is one of the most promising materials used to create the Gunn diodes and HEMT of millimeter and submillimeter bands [1-6]. The parameters of the active elements are essentially determined by the quality of initial InP and electrical and physical properties of ohmic contacts [7-11]. Therefore, along with improvement of manufacturing technology of InP and InP-based solid solutions, there intensively developed are the processes of formation of multilayer ohmic contacts for both vertical and planar options of device structures. It is primarily related with the very small sizes of the operating InP layers used in devices of the millimeter and submillimeter bands, which requires a sharp, uniform and thermally stable interface 'contactforming layer - InP'. It is very important for Gunn diodes. Another feature of the ohmic contacts to Gunn diodes is providing a minimum value of the specific contact resistance $\rho_{c}$, which is achieved or by creation of epitaxial structure with heavily doped top layer $n^{+}\left(n^{+}-n-\right.$ $n^{++}-n^{+++}$-InP-structure), or by formation of this upper subcontact layer in the manufacturing process of ohmic contacts through doping with donor impurity of contactforming intermetallic compounds, for example, AuGe, AuSn, PtSi [11-13], or by using heterojunction as a subcontact layer [11]. Here, the contact-forming layer to the indium phosphide Gunn diodes, as to GaAs ones, is mostly created by eutectic Au-Ge alloy, providing the lowest possible specific contact resistance. However, in this case, because of appearance of a number of lowtemperature binary, ternary or multicomponent phases with different electron work functions $\varphi$, it is difficult to provide a rather uniform ohmic contact $[14,15]$. For example, according to the data [16] GeP phase appears at the temperature $\sim 320^{\circ} \mathrm{C}$, AuIn - at $\sim 250{ }^{\circ} \mathrm{C}$ [17], a 
quadruple phase of AuGeInP - within the temperature range $300 \ldots 370{ }^{\circ} \mathrm{C}[18], \mathrm{Au}_{2} \mathrm{P}_{3}-$ at the temperature $395{ }^{\circ} \mathrm{C}$ [19]. With regard to the work function of the intermetallic compounds similar to the above, according to the data [17], the value of $\varphi$ for $\mathrm{Au}_{10} \mathrm{In}_{3}$ and $\mathrm{GeP}$ is not less than $\varphi$ for InP, that is $\sim 4.6 \mathrm{eV}$ for InP (100) and $\sim 5.6 \mathrm{eV}$ for InP (110) [20]. It means that with a high probability these phases can promote formation of local rectifying contacts with different Schottky barrier heights, which causes the appearance of an inhomogeneous contact. If the difference in the work functions is small (Schottky barrier), then this contact may be an ohmic one. Note here that depending on the heat treatment conditions (e.g., ohmic contact formation mode during annealing), phases occurring at relatively low temperatures do not break down also at higher temperatures. Thus, in [16] it was shown that the phases $\mathrm{Au}_{3} \mathrm{In}$ and $\mathrm{Au}_{2} \mathrm{P}_{3}$ formed during annealing at $T=320{ }^{\circ} \mathrm{C}$ for 2 hours also retained after annealing at $T=400{ }^{\circ} \mathrm{C}$ for 2 hours, and the phase $\mathrm{Au}_{2} \mathrm{P}_{3}$ retained even after annealing at $T=450{ }^{\circ} \mathrm{C}$ for 2 hours. At the same time, a new phase $\mathrm{Au}_{9} \mathrm{In}_{4}$ appears, and the ohmic contact retains non-uniform. Because of this, the search for the contact systems free from deficiencies of contacts based on relatively low-temperature eutectic layers is not stopped $[21,22]$. One of such systems is contact metallization with the Pd-based contact-forming layer [17, 23-25]. In this case, according to [23-25], the ohmic contact formed by the amorphous phase $\mathrm{Pd}_{2} \mathrm{InP}$, arising at $T \approx 250{ }^{\circ} \mathrm{C}$ and stable to $T=400{ }^{\circ} \mathrm{C}$. To improve the reliability of contacts between contact-forming layer and upper gold coating, deposited is a conductive film that does not react with $\mathrm{Au}$ and contact-forming layer, the so-called diffusion barrier. As a diffusion barrier, one can use films of refractory metals or alloys, for example, borides, carbides, nitrides of refractory metals [26]. In this work, in contrast to the known publications about $\mathrm{Pd}$ ohmic contacts to InP, where for creating a contact the various heat treatments, including rapid thermal annealing (RTA), were used, deposition of $\mathrm{Pd}$ was carried out onto a heated $n^{+}-n-n^{++}-n^{+++}$-InP structure, $n^{+}$layer of which is grown by the vapor phase epitaxy method [27]. A diffusion barrier between the upper contact $\mathrm{Au}$ layer and contact-forming layer was a titanium film. Following are discussions of the structural and electrical properties of these contacts, as well as electrical characteristics of Gunn diodes.

\section{Samples and research methods}

We studied two types of samples: test structures and models of Gunn diodes made using epitaxial $n^{+}-n-n^{++}$. $n^{+++}$-InP structures with carrier concentrations in the $n^{+}$layer $\sim 10^{18} \mathrm{~cm}^{-3}$, in the $n$-layer $\sim 8 \cdot 10^{15} \mathrm{~cm}^{-3}, n^{++}$-layer $\sim 5 \cdot 10^{17} \mathrm{~cm}^{-3}, n^{+++}$-layer $2 \cdot 10^{18} \mathrm{~cm}^{-3}$ and with the thicknesses of $0.2,1.5$ and $300 \mu \mathrm{m}$, respectively.

The ohmic contacts were created using successive vacuum deposition of metals onto a heated to $300{ }^{\circ} \mathrm{C}$ epitaxial InP structure. The ohmic contact $\mathrm{Au}(100 \mathrm{~nm})-$
Ti(40nm)-Pd(30nm)- $n^{+}-$InP was formed during the deposition process and was not additionally annealed. The test structures with continuous metallization $\mathrm{Au}(100 \mathrm{~nm})-\mathrm{Ti}(40 \mathrm{~nm})-\mathrm{Pd}(30 \mathrm{~nm})-n^{+}-n-n^{++}-n^{+++}-\mathrm{InP}$ were used to measure the phase composition and profiles of the distribution of component of the contact metallization by the methods of X-ray diffraction and Auger electron spectroscopy, respectively. X-ray diffraction measurements were carried out on the setup ARL X'Tra (Thermo scientific) with using $\mathrm{CuK}_{\lambda}$ radiation. The tube voltage was $45 \mathrm{kV}$, current was $30 \mathrm{~mA}$. The diffraction spectra were measured using a sliding beam. Measurements were performed in the incremental mode with scanning pitch $0.030^{\circ}$ and the time set at each position $1 \mathrm{~s}$. The phase analysis was performed using a database ICDD, PDF-2 Release 2012. The elemental composition and Auger electron spectra of the components of the contact metallization were measured using the Auger spectrometer LAS-2000. On the planar test structures, by using the transmission line method (TLM), the specific contact resistance $\rho_{c}$ was measured [10].

Gunn diodes were fabricated in a straight mesa structure according to the flowsheet proposed by us, which is shown in Fig. 1. The corresponding chip of active element is shown in Fig. 2.

On Gunn diodes assembled in metal body, measured were current-voltage characteristics (CVC) at room temperature in the pulsed mode and the output power at the V-band.

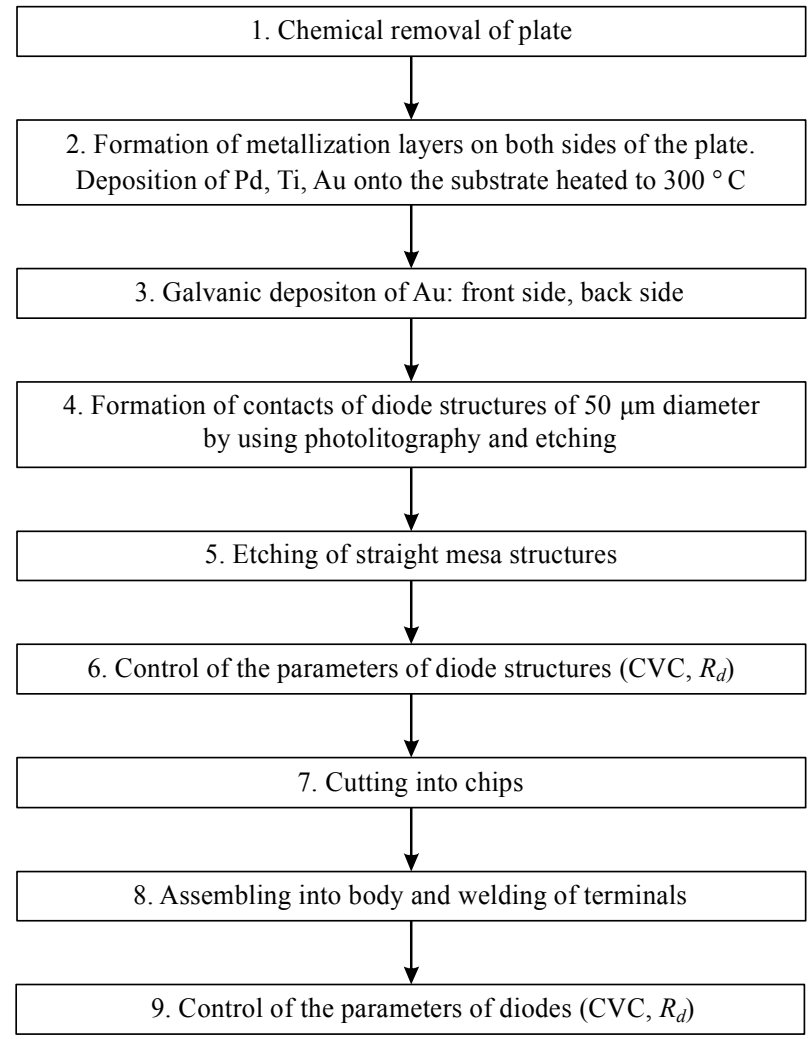

Fig. 1. Flowsheet scheme of manufacturing Gunn diodes based on InP in the form of a straight mesa structure. 


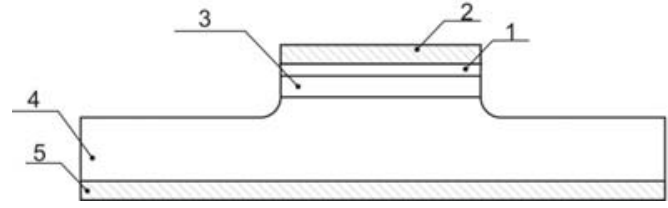

Fig. 2. General view of the chip of active element of InP Gunn diode in the form of a straight mesa structure. $1-n^{+}$contact InP layer; 2 -an ohmic contact to the $n^{+}$-layer of InP; $3-$ operating InP layer; $4-n^{++}-n^{+++}$structure of InP; $5-$ ohmic contact to the $n^{+++}$-InP substrate.

\section{Experimental results and discussion}

Fig. 3 shows the profiles of distribution of the components in contact metallization $\mathrm{Au}-\mathrm{Ti}-\mathrm{Pd}-\mathrm{InP}$. It is evident that there is the layered structure of the deposited metal films with appreciable content of oxygen and carbon in the titanium film. The Auger spectra after sequential etching of the layers $\mathrm{Au}, \mathrm{Ti}, \mathrm{Pd}$ are shown in Figs. $4 a$, and $4 b, 4 c$, respectively. It is seen that after removing the gold film, on the surface of titanium layer, fixed were residues of non-etched $\mathrm{Au}$, as well as $\mathrm{Ti}, \mathrm{O}, \mathrm{C}$, traces of $\mathrm{Cu}$ and $\mathrm{S}$, in the palladium film - In, Ti, P and O. After removal (etching) of all the layers of contact metallization, a "clean" surface of InP is observed. These results correlate with X-ray phase analysis data (Fig. 5). In the X-ray diffractogram, there are only two peaks corresponding to the reflections of the polycrystalline Au layers (Pdf Number 010-77-9662) and Ti (Pdf Number 010-88-2321). As for palladium, the reflections corresponding to it or its compounds were not found, which may be associated with a small amount of deposited Pd or phase formed with his participation. Furthermore, since the Pd profile is fixed when analyzing the elemental composition of the contact metallization with Auger electron spectroscopy (Fig. 3) and in the corresponding Auger spectra (Fig. 4) after removal of the $\mathrm{Au}$ and Ti layers, it can be assumed that palladium or the phase formed by Pd with semiconductor components is in an amorphous state, which does not contradict the literature data about creating ohmic contacts to $n$-InP based on $\mathrm{Pd}[17,23-25]$. Morphology of the surface layer containing $\mathrm{Pd}$ and its uniform etching as well as relatively homogeneous morphology of InP surface after removing all the contact metallization layers indicate the absence of multiphase in contact-forming layer.

On the TLM structures fabricated on the front (from the side of $n^{+}$-layer of InP) and back (from the side of $n^{+++}$-substrate) InP surfaces, current-voltage characteristics and $\rho_{c}$ were measured within the temperature range $110 \ldots 380 \mathrm{~K}$. It was found that from both sides of the InP plate, the current-voltage characteristics measured at room temperature were linear, and the $\rho_{c}$ values were close and equal to $7 \cdot 10^{-5} \mathrm{Ohm} \cdot \mathrm{cm}^{2}$. It corresponds to $\rho_{c}$ given in [23] and characterizing the ohmic properties of a single-layer palladium contact on heavily doped $\left(n^{+} \approx 10^{18} \mathrm{~cm}^{-3}\right) \mathrm{InP}$ substrate with followed RTA at $T=300 \ldots 350^{\circ} \mathrm{C}$.

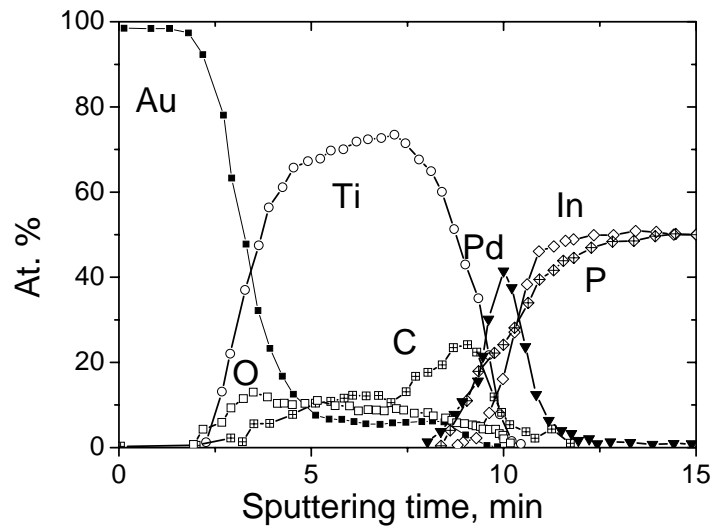

Fig. 3. Profiles of component distributions in the contact metallization $\mathrm{Au}-\mathrm{Ti}-\mathrm{Pd}-n^{+}-\mathrm{InP}$.
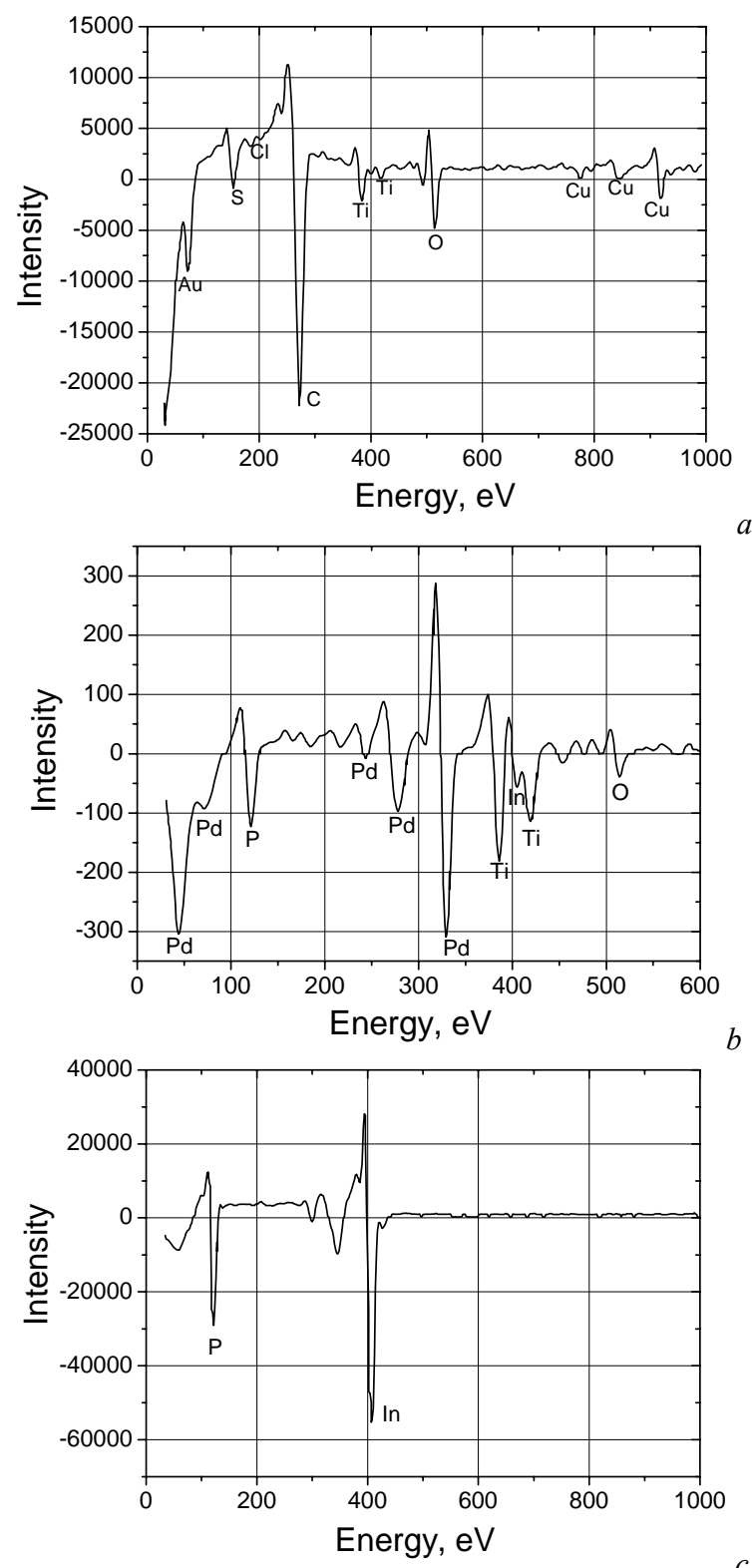

Fig. 4. Auger spectra after removing (etching) of the layers $\mathrm{Au}(a), \mathrm{Ti}(b)$ and $\mathrm{Pd}(c)$. 
Note also that in the whole temperature range measured by us, the current-voltage characteristics were linear. A typical family of current-voltage characteristics of an ohmic contact from the part of $n^{+}$-layer is shown in the inset in Fig. 6. The temperature dependence of $\rho_{c}$ is presented in Fig. 6 . At $T>150 \mathrm{~K}, \rho_{c}$ decreases with increasing the temperature. Plotting the dependence $\rho_{c}(T)$ in the coordinates $\rho_{c}=f\left(10^{3} / T\right)$, it is easy to see that at $T>$ $150 \mathrm{~K}$, the dependence $\rho_{c}(T)$ is exponential, which is typical for thermofield or thermionic current transport mechanism. We have suggested that in this case the thermofield mechanism of current flowing through a contact is realized. Theoretical dependence $\rho_{c}(T)$ was constructed using the modified formula (127) presented in the third chapter of the monograph by S.M. Sze, Kwok K. Ng [28] of the form:

$$
\rho_{T F}=\frac{k \sqrt{E_{00}} \cosh \left(\frac{E_{00}}{k T}\right) \operatorname{coth}\left(\frac{E_{00}}{k T}\right)}{A\left(\frac{m^{*}}{m_{0}}\right) T q \sqrt{\pi\left(\varphi_{c}-E_{\mathrm{F}}\right)}} \times \exp \left[\frac{\varphi_{c}-E_{\mathrm{F}}}{E_{00} \operatorname{coth}\left(\frac{E_{00}}{k T}\right)}+\frac{E_{\mathrm{F}}}{k T}\right]
$$

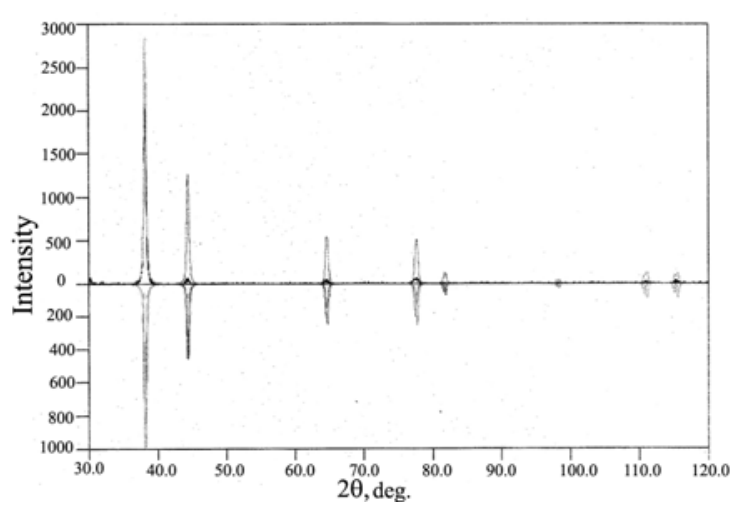

Fig. 5. The experimental diffraction pattern of the contact metallization $\mathrm{Au}-\mathrm{Ti}-\mathrm{Pd}-n^{+}-\mathrm{InP}$.

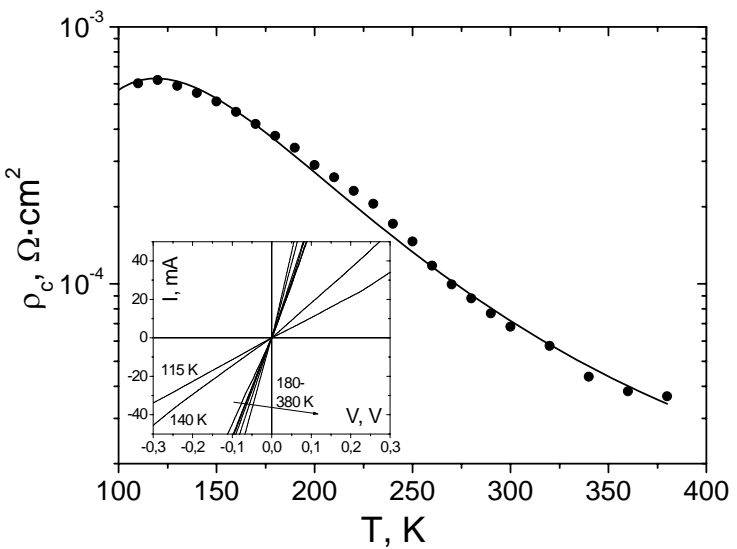

Fig. 6. Temperature dependence of the ohmic contact $\rho_{c}$ $\mathrm{Au}-\mathrm{Ti}-\mathrm{Pd}-n^{+}-\mathrm{InP}$, points correspond to the experiment, lines calculation. The inset shows the current-voltage characteristics for ohmic contact measured in the temperature range from 115 to $380 \mathrm{~K}$. where $\rho_{T F}$ - specific contact resistance in the case of implementation of thermofield mechanism of current transport, $k$ - Boltzmann's constant, $T$ - temperature, $q$ is an elementary charge, $\varphi_{c}-$ the potential energy of electron, that is, the barrier height at the interface metalsemiconductor, measured from the bottom of the conduction band of semiconductor, $m_{n}^{*}$ - the effective mass of electron, $E_{00}=0.054\left(\left(m_{0} / m^{*}\right)\left(N_{d} / 10^{20}\right)\left(11.7 / \varepsilon_{s}\right)\right)^{0.5}-$ characteristic energy of tunneling, $\varepsilon_{s}$ - dielectric constant of semiconductor, $A-$ Richardson constant, $E_{\mathrm{F}}(T)-$ Fermi energy.

As can be seen from comparing the experimental and theoretical dependences, they are in good agreement with each other. Coincidence is achieved in the case where the barrier height is $0.28 \mathrm{eV}$.

The data obtained on $\rho_{c}(T)$ as well as the phase and chemical composition of the contact metallization point to relatively uniform interface contact-forming layer InP, formed directly in the course of deposition of contact metallization on InP substrate heated to $300{ }^{\circ} \mathrm{C}$ without subsequent heat treatment.
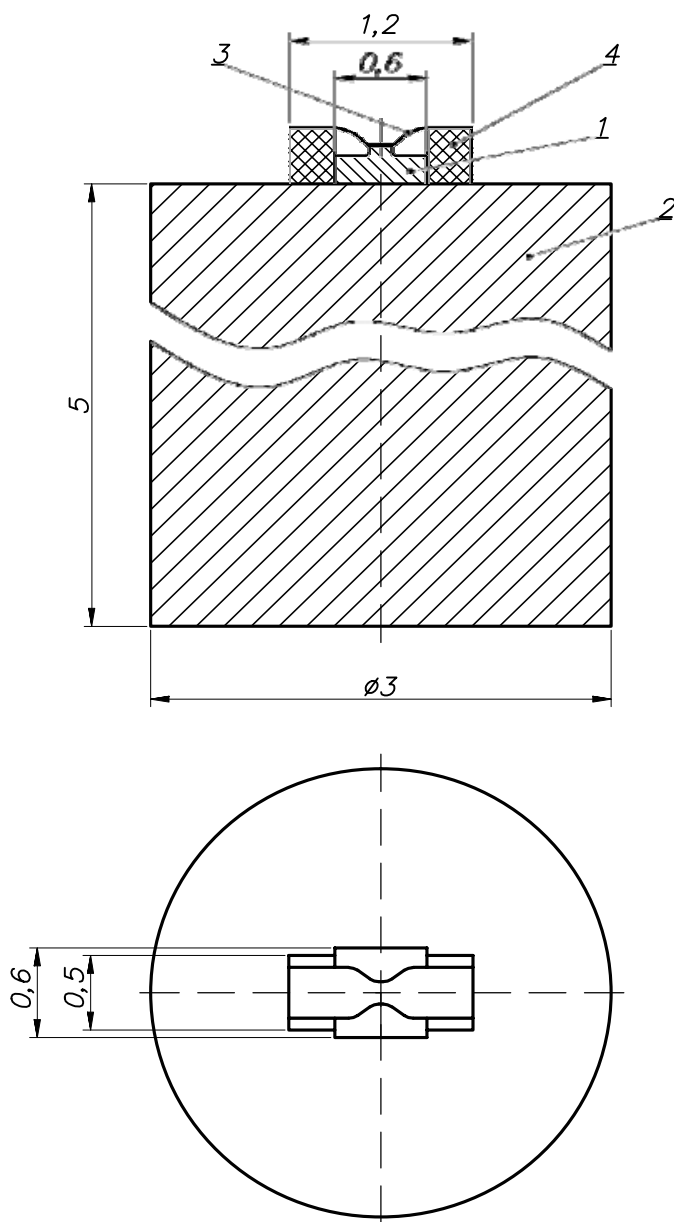

Fig. 7. The design of a prototype for InP Gunn diode: a) side view, b) top view: 1 - chip, 2 - holder, 3 - output to the upper contact, 4 - dielectric supports with metallized ends, 5 - mesa structure of the Gunn diode. Dimensions are in millimeters. 
Table. Geometrical and physical parameters of the diode chip used when calculating the maximum heating temperature of the active layer [34].

\begin{tabular}{|c|c|c|c|c|c|c|}
\hline \multirow{2}{*}{$\begin{array}{c}\text { Designation of } \\
\text { dimensions }\end{array}$} & \multirow{2}{*}{$\begin{array}{c}\text { Sizes, } \\
\mu \mathrm{m}\end{array}$} & \multirow{2}{*}{ Material } & \multicolumn{4}{|c|}{ Physical parameters } \\
\cline { 4 - 7 } & & $\rho, \mathrm{g} / \mathrm{cm}^{3}$ & $\lambda, \mathrm{W} / \mathrm{cm} \cdot \mathrm{K}$ & \multicolumn{2}{c|}{$c / \mathrm{g} \cdot \mathrm{K}$} & $\alpha, \mathrm{cm} / \mathrm{s}$ \\
\hline $\mathrm{d} 1$ & 50 & & & & & \\
\hline $\mathrm{h} 1$ & 1 & $\mathrm{InP}$ & 4.81 & 0.68 & 0.31 & 0.456 \\
\hline $\mathrm{h} 2$ & 0.3 & $\mathrm{InP}$ & 4.81 & 0.68 & 0.31 & 0.456 \\
\hline $\mathrm{h} 3$ & 4 & $\mathrm{Au}$ & 19.32 & 3.17 & 0.128 & 1.28 \\
\hline
\end{tabular}

Here: $\rho$ is the density, $\lambda$ - coefficient of thermal conductivity, $c$ - specific heat, $\alpha$ - thermal diffusivity coefficient of chip components.

Diode chips, made with these contacts, in the form of straight mesa structure with a diameter of $50 \mu \mathrm{m}$ were mounted in the metallic-and-ruby bodies. The design of a prototype InP Gunn diode with contact metallization of $\mathrm{Au}-\mathrm{Ti}-\mathrm{Pd}-n^{+}-\mathrm{InP}$ is shown in Fig. 7. Fig. 8 shows the current-voltage characteristics of this diode, measured in a pulsed mode with pulse duration of $100 \mathrm{~ns}$ and pulse ratio of 1000 . From Fig. 8 , it is seen that the critical voltage of the Gunn diode is $2 \mathrm{~V}$. These diodes generate a microwave power in the V-band up to $10 \mathrm{~mW}$. Operating current was 1.7 to $2.2 \mathrm{~A}$ depending on the diameter of the mesa structure.

Since the output parameters of generating microwave diodes are largely limited to the thermal conditions of operation, especially overheating [29-31], it seems appropriate to estimate the maximum temperature of the active layer of discussed above InP Gunn diode depending on the pulse duration and the temperature distribution along the axis $Z$. Moreover, at prolonged operation of the diode this temperature may affect the interfacial interactions in the ohmic contacts. Calculations were carried out in the ePhysics shell [32] in accordance with the known finite element method described in [33]. The inset in Fig. 9 shows the model structure of the Gunn diode chip adopted for the calculation. The geometric and thermal parameters necessary to calculate as well as values of the density for the chip components are presented in Table. The calculations were performed for two values of dissipated power -30 and $20 \mathrm{~W}$ at pulse duration of $100 \mathrm{~ns}$ and pulse ratio of 1000 .

Fig. 9 shows the results of calculations of the maximum heating temperature of the active layer depending on the pulse duration for the dissipated power $30 \mathrm{~W}$ and for the same dissipated power - the temperature distribution along the axis $Z$ (Fig. 10). It is seen that up to $T=210^{\circ} \mathrm{C}$, the diode is heated when the pulse duration is $100 \mathrm{~ns}$, and the maximum heating is in the active region of the diode of length 1.5-2 $\mu \mathrm{m}$. If the dissipated power is $\sim 20 \mathrm{~W}$ and pulse duration is $\sim 100 \mathrm{~ns}$, the diode is heated to $T=145^{\circ} \mathrm{C}$. Heat dissipation in a straight mesa structure is performed through the InP substrate. Considering the data from the literature [17, 23-25] on the Pd-based ohmic contact and the above estimations for thermal parameters of Gunn diodes, we can suppose that the ohmic contacts, considered by us under the assumption of presence of contact-forming amorphous layer containing the components of $\mathrm{Pd}$, In and $\mathrm{P}$, will be stable at this heat mode. The additional annealing of the back contact $\mathrm{Au}-\mathrm{Ti}-\mathrm{Pd}-n^{+++}-\mathrm{InP}$ conducted at $T=350{ }^{\circ} \mathrm{C}$ for $1.5 \mathrm{~min}$ did not practically change the value $\rho_{c}$, which confirms the version about the thermal stability of the ohmic contacts $\mathrm{Au}-\mathrm{Ti}-\mathrm{Pd}-$ $n^{+}-\mathrm{InP}$.

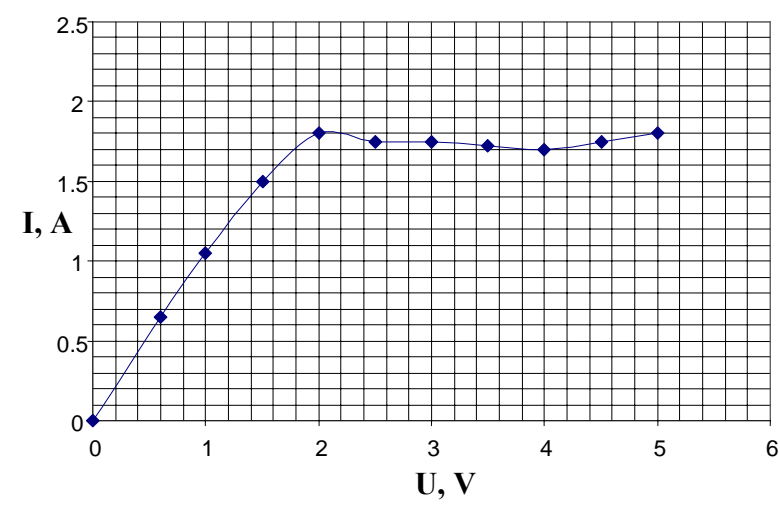

Fig. 8. Typical pulse current-voltage characteristics of InP Gunn diode, measured at the temperature $300 \mathrm{~K}$. The pulse duration $100 \mathrm{~ns}$, pulse ratio 1000 .

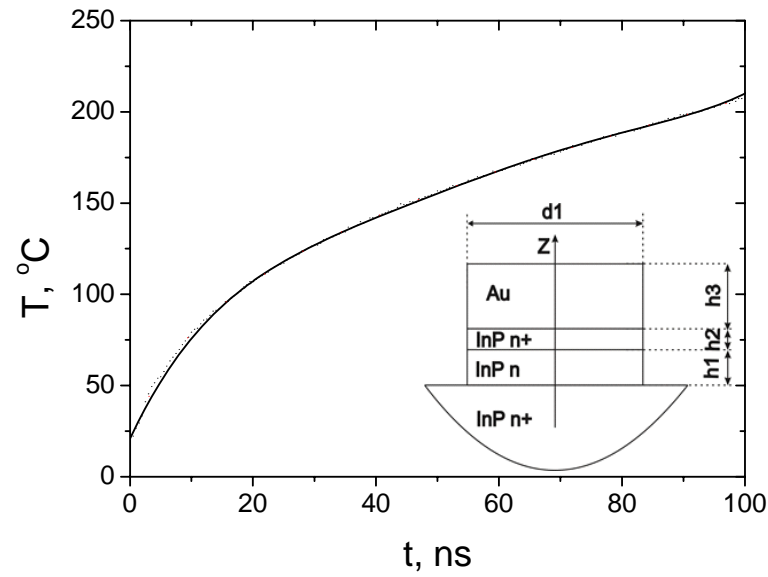

Fig. 9. Dependence of the maximum temperature of the active layer in Gunn diode on the pulse duration when the pulse ratio is 1000 and dissipated power is $30 \mathrm{~W}$. The inset shows the diode structure adopted for thermal calculations. 


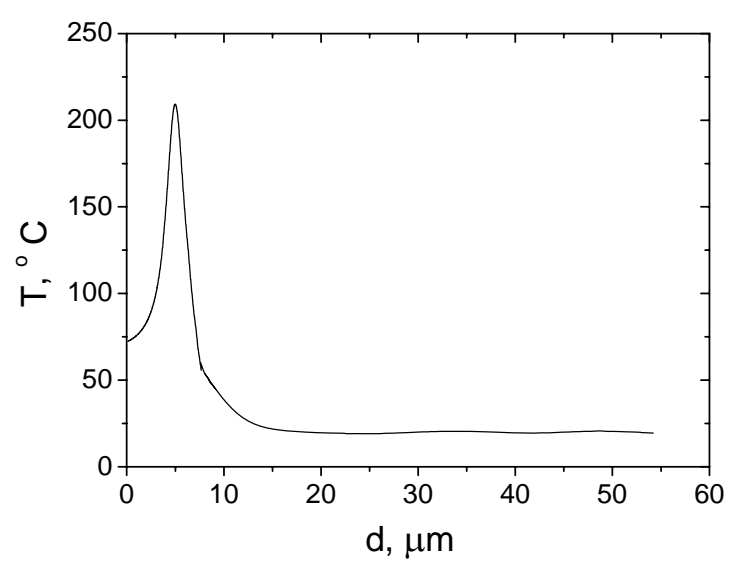

Fig. 10. The temperature distribution along the axis $Z$. The pulse duration of $100 \mathrm{~ns}$, when the pulse ratio 1000 . The dissipated power is $30 \mathrm{~W}$.

\section{Conclusions}

1. Suggested has been the flowsheet of producing pulse indium phosphide Gunn diodes in the form of a straight mesa structure with creating lowresistance ohmic contacts by successive deposition of metals $\mathrm{Pd}, \mathrm{Ti}$, and $\mathrm{Au}$ in one process cycle onto a substrate heated to $300{ }^{\circ} \mathrm{C}$ without subsequent annealing.

2. It has been determined that the current-voltage characteristics of ohmic contacts obtained in the course of successive deposition of metals $\mathrm{Pd}, \mathrm{Ti}$ and $\mathrm{Au}$ onto a InP substrate heated $300{ }^{\circ} \mathrm{C}$ are linear within the temperature range $110 \ldots 380 \mathrm{~K}$, and the dependence $\rho_{c}(T)$ is described by thermofield mechanism of current transport. At $T=$ $300 \mathrm{~K}, \rho_{c}$ is close to $7 \cdot 10^{-5} \mathrm{Ohm} \cdot \mathrm{cm}^{2}$ for ohmic contacts obtained from the front and back sides of the epitaxial structure $n^{+}-n-n^{++}-n^{+++}-\operatorname{InP}$.

3. It has been shown that microwave generation of the capacity up to $10 \mathrm{~mW}$ is observed in a pulsed mode with a pulse duration of $\sim 100 \mathrm{~ns}$, pulse ratio 1000 , operating current $\sim 2.2 \mathrm{~A}$ in the $\mathrm{V}$ frequency range in indium phosphide Gunn diode, fabricated in the form of a straight mesa structure.

4. Presented have been estimations of the maximum heating temperature of the active layer of InP Gunn diode made in the form of a straight mesa structure corresponding to $210^{\circ} \mathrm{C}$ and a maximum in the temperature distribution along the $Z$ axis in the active diode region with the length of $\sim 1.5-2 \mu \mathrm{m}$ at the dissipated power $30 \mathrm{~W}$, pulse duration $100 \mathrm{~ns}$ and pulse ratio 1000 .

\section{References}

1. H. Eisele, R.Kamua, Submillimeter-wave InP Gunn devices // IEEE Trans. MTT, 52(10), p. 2371-2378 (2004).
2. H. Eisele, R. Kamoua, High-perfomance oscillators and power combiners with InP Gunn devices at 260-330 GHz // IEEE MWCL, 16(5), p. 284-286 (2006).

3. H. Eisele, Third-harmonic power extraction from InP Gunn devices up to $455 \mathrm{GHz} / /$ IEEE $M W C L$, 19(6), p. 416-418 (2009).

4. H. Eisele, $480 \mathrm{GHz}$ oscillator with the InP Gunn devices // Electron. Lett. 46(6), p. $422-423$ (2010).

5. V. Papageorgiou, A. Khalid, C. Li, D.R.S. Cumming, Cofabrication of planar Gunn diode and HEMT on InP substrate // IEEE Trans Electron. Dev. 61(8), p. $2779-2784$ (2014).

6. M.I. Maricar, A. Khalid, G. Dunn, D. Cumming, C.H. Oxley, Experimentally estimated dead space for GaAs and InP based planar Gunn diodes // Semicond. Sci. Technol. 30, 012001-012005 (2015).

7. M.E. Levinstein, Yu.K. Pozhela, M.S. Shur, Gunn Effect. Sov. Radio, Moscow, 1975 (in Russian).

8. Indium Phosphide: Crystal Growth and Characterization, Eds. R.K. Willardson, A.C. Beer // Semiconductor and Semimetals, vol. 31, Academic Press Inc. New York. USA. 1990.

9. S.M. Sze, Modern Semiconductor Device Physics. Wiley. New York. USA. 2006.

10. D.K. Schroder, Semiconductor Materials and Devices Characterization. Wiley. New York. USA. 2006.

11. Contacts to Semiconductors. Fundamentals and Technology. Ed. by J. Brillson. Noyes Publ. N.J. USA. 1993.

12. P.A. Barnes, R.S. Williams, Alloyed tin-gold ohmic contacts to $n$-type indium phosphide // SSE, 24(10), p. 907-913 (1981).

13. W.C. Huang, Effect of Au overlayer on PtSi ohmic contacts with $n$-InP // Appl. Surf. Sci. 245(1), p. 141-148 (2005).

14. R.T. Tung, The physics and chemistry of the Schottky barrier height // J. Appl. Phys. Rev. 1, 011304-1-011304-54 (2014).

15. A.V. Shmargunov, Non-linear dependence of the barrier height on the bias and nature of anomaly inherent to characteristics of contacts with Schottky barrier // Abstracts of theses (Cand. Phys. and Math. Sciences). Tomsk State University, Russian Federation, 2015 (in Russian).

16. P. Auvray, A. Guivarch, H. L'Haridon, J.P. Mercier, Formation, microstructure et resistances des contacts $\mathrm{Au}-\mathrm{Ge} / \mathrm{n}-\mathrm{GaAs}, \mathrm{Au}-\mathrm{Ge} / \mathrm{n}-\mathrm{InP}, \mathrm{Au}-\mathrm{Zn} / \mathrm{p}-\mathrm{InP}$ et $\mathrm{Au}-$ Be/p-InP // TSF, 127(1), p. 39-68(1985).

17. Ping Jian, D.G. Ivey, R. Bruce, G. Knight, Ohmic contact formation in palladium-based metallization to n-type InP // J. Electron. Mater. 23(9), p. 953962 (1994).

18. T. Clausen, O. Leistiko, Metallurgical optimization for ohmic contacts to InP using conventional metallization schemes // Microelectron. Eng. 18(4), p. 305-325 (1992). 
19. N.S. Fatemi, V.G. Weizer, The formation of low resistance electrical contacts to shallow junction InP devices without compromising emitter integrity // J. Electron. Matter. 20(10), p. 875-880 (1991).

20. V.S. Fomenko, Emission Properties of Materials. Naukova dumka, Kiev, 1981 (in Russian).

21. Wu Deqi, Ding Wuchang, Yang Shanshan, Jia Rui, Jin Zhi, Liu Xinyu. Optimization of ohmic contact for InP-based transferred electronic devices // J. Semiconductors, 35(3), 036001-1-036001-5 (2014).

22. M.A. Abraham, S-Y. Yu, W.H. Choi, R.T.P. Lee, S.E. Mohney, Very low resistance alloyed Ni-based ohmic contacts to InP-capped and uncapped $\mathrm{n}^{+} \mathrm{In}_{0.53} \mathrm{Ga}_{0.47} \mathrm{As} / / \mathrm{J}$. Appl. Phys. 116(16), 16450611645066 (2014).

23. D.G. Ivey, Platinum metals in ohmic contacts to III-V semiconductors // Platinum Metals Rev. 43(1), p. 2-12(1999).

24. Avishai Katz, Physical and Chemical Deposition of Metals as Ohmic Contacts to InP and Related Materials. Chap. 4. In: Handbook of Compound Semiconductors: Growth, Processing, Characterization and Devices. Eds. P.H. Holloway, G.E. McGuire. Noyes Publ. Park Ridge, New Jersey, USA, 1995.

25. S.J. Pearton, Processing of Wide Band Gap Semiconductors: Growth, Processing and Applications. Noyes Publ. Park Ridge. New Jersey, USA, 2000.

26. A.E. Belyaev, N.S. Boltovets, R.V. Konakova, Ya.Ya. Kudryk, V.V. Milenin, Diffusion barriers in ohmic contacts to semiconductors device structures: Technology, Properties, Application. Chap.4.
In: Advances in Materials Science Research, vol. 12. Ed. M.C. Wythers. Nova Sci, USA, 2012.

27. I.N. Arsentyev, A.V. Bobyl, I.S. Tarasov et al., New technological possibilities to prepare InP epitaxial layers, as well as ohmic and barrier contacts to them and the properties of microwave diodes made on their basis // Semiconductor Physics, Quantum Electronics and Optoelectronics, 8(4), p. 105-114 (2005).

28. S.M. Sze, Kwok K. Ng, Physics of Semiconductor Devices. $3^{\text {rd }}$ ed. Wiley, New Jersey, USA. 2007.

29. L.V. Kasatkin, V.Ye. Chaika, Semiconductor Devices of Millimeter Waveband. Veber, Sevastopol, 2006 (in Russian).

30. A.E. Belyaev, V.V. Basanets, N.S. Boltovets et al., Effect of $p-n$ junction over heating on degradation of silicon high-power pulsed IMPATT diodes // Semiconductors, 45(2), p. 253-259 (2011).

31. A.V. Garmatin, Effect of heating on energetic characteristics of Gunn diodes based on GaAs and InP of millimeter wave band // Elektronnaia tekhnika. Ser. SVCh, 6(354), p. 17-20 (1983), in Russian.

32. http://www.ansoft.com/products/tools/ephysics.

33. A.V. Gutsul, O.V. Zorenko, Thermal conditions analysis of impat diodes in millimeter-wave pulse generators // Bulletin of National Technical University of Ukraine "KPI”. Ser. Radiotechnique. Radioapparatus Building. No. 36, p. 76-80 (2008), in Ukraine.

34. Physical Values. Handbook. Eds. I.S. Grigoriyev and Ye.Z. Melikhov. Energoatomizdat, Moscow, 1991 (in Russian). 